\title{
1 Adsorption of butanol vapor on active carbons with nitric acid
}

2 hydrothermal modification

3

$4 \quad$ Han Vu

5

6

7

8

9

10

11

12

13

14

15

16

17

18

19

20

21

列

列

1

2

3

4

5

6

17

22 Tel: +1-605-688-5372 Fax: +1-605-688-6764 Email: Zhengrong.gu@ @dstate.edu

23 1.These authors contributed equally to this work.

${ }^{a}$ Agricultural and Biosystems Engineering Department, South Dakota State University, Brookings, SD, USA

${ }^{\mathrm{b}}$ Department of Biology and Microbiology, South Dakota State University, Brookings, SD, USA

${ }^{\mathrm{c}}$ Department of Chemistry, Amherst College, Amherst, MA, USA

8 *Correspondence:

Zhengrong $\mathrm{Gu}$

North Campus Drive 1400, Agricultural and Biosystems Engineering, South Dakota State

1 University, Brookings, SD 57007, USA 


\section{Abstract}

25 Butanol can be produced from biomass via fermentation and used in vehicles.

26 Unfortunately, butanol is toxic to the microbes, and this can slow fermentation rates and reduce

27 butanol yields. Butanol can be efficiently removed from fermentation broth by gas stripping,

28 thereby preventing its inhibitory effects. Original active carbon (AC) and AC samples modified

29 by nitric acid hydrothermal modification were assessed for their ability to adsorb butanol vapor.

30 The specific surface area and oxygen-containing functional groups of $\mathrm{AC}$ were tested before and

31 after modification. The adsorption capacity of unmodified AC samples were the highest.

32 Hydrothermal oxidation of $\mathrm{AC}$ with $\mathrm{HNO}_{3}$ increased the surface oxygen content, Brunauer-

33 Emmett-Teller (BET) surface area, micropore, mesopore and total pore volume of AC. Although

34 the pore structure and specific surface area were greatly improved after hydrothermal oxidization

35 with $4 \mathrm{M} \mathrm{HNO}_{3}$, the increased oxygen on the surface of $\mathrm{AC}$ decreased the dynamic adsorption

36 capacity.

37 Keyword: butanol; hydrothermal; gas stripping; active carbon; $\mathrm{HNO}_{3}$ 


\subsection{Introduction}

High fuel prices and climate change are two critical challenges in the world. Fossil fuels, particularly petroleum-based fuels such as gasoline, diesel fuel, liquefied petroleum gas, and

41 natural gas are mainly used for transportation, and will become increasingly difficult to access in

42 the next few decades (Lin et al., 2011). Liquid biofuels such as biobutanol (Gottumukkala et al.,

43 2013), bioethanol (Kim et al., 2014), and biodiesel (Manickam et al., 2014) have the potential to

44 reduce the need for petroleum fuels. These biofuels can also reduce greenhouse gas emissions

45 compared to petroleum-based fuels (Zhao et al., 2015).

Biobutanol has several advantages over other biofuels such as ethanol, including higher

47 energy density and lower water miscibility, flammability, and corrosiveness. Butanol is also

48 considered an infrastructure compatible fuel, as it can be blended in any ratios with gasoline

49 without requiring engine modifications (Xue et al., 2013). Butanol can also be transported using

50 the same pipelines and distribution networks that are currently used for petroleum products.

51 Butanol is primarily produced via the bacterial acetone-butanol-ethanol (ABE) fermentation

52 pathway (Bellido et al., 2014; Yen \& Wang, 2013).

53 One of the chief limitations of butanol is that it is highly inhibitory to the microbes used

54 to produce it. Levels as low as $13.0 \mathrm{~g} / \mathrm{L}$ can cause reduced growth and metabolism (Setlhaku et

55 al., 2013). Butanol recovery from dilute fermentation broth is quite expensive, and this has been

56 a major hurdle to commercialization. Distillation (Kraemer et al., 2011) is widely used to recover

57 volatile fermentation products, but is not practical for butanol due to high energy requirements

58 (Oudshoorn et al., 2009b). Membrane distillation (Plaza et al., 2013) and pervaporation

59 (Kujawski et al., 2014) have been suggested, but membrane fouling by organic compounds in the

60 fermentation slurry has been an issue. Liquid phase adsorption (Cousin Saint Remi et al., 2012; 
61 Oudshoorn et al., 2009a; Saint Remi et al., 2011) and liquid-liquid extraction (Ha et al., 2010)

62 are often limited by the toxicity of the liquid absorbents to the microbial culture.

A more economical method of recovering butanol from dilute fermentation streams may

64 be gas stripping (de Vrije et al., 2013; Liao et al., 2014; Plaza et al., 2013). Gas stripping is a

65 relatively simple process in which a gas is continuously bubbled through the fermentation culture

66 to volatilize and carry out the chemical (as well as some water vapor), which are subsequently

67 condensed (Luo et al., 2006). The challenge with applying gas stripping to butanol fermentation

68 is that the gas stream exiting the fermentor would also be very dilute. The condensation

69 temperature required to condense butanol from a vapor stream is directly correlated with the

70 butanol concentration. Therefore, a dilute butanol vapor would require exceptionally cold

71 condensation temperatures, such as that of liquid nitrogen (Liao et al., 2014). These added costs

72 would negate the benefits of gas stripping. To overcome this challenge, an alternative to direct

73 condensation is to pass the gas stripping vapor first into an absorbent to concentrate the chemical.

74 A smaller volume of gas can subsequently be used to displace the chemical from the absorbent,

75 resulting in a higher concentration in this secondary vapor, such that cold water could be used to

76 condense the product.

77

Activated carbon (AC) has been widely employed to adsorb volatile organic compounds

78 (benzene, toluene, formaldehyde, n-hexane, butanol, and ethanol) from gas streams that are

79 generated from a wide range of industries (Subrenat \& Le Cloirec, 2004). AC has a large surface

80 area, high porosity, a variety of pore sizes and structures, and rapid adsorption capabilities. Thus

81 AC may provide an economical option for recovering and concentrating butanol in gas stripping

82 vapor. However, prior work on the adsorption behavior of AC has not adequately addressed the 
effects of adsorption temperature, concentration, and regeneration, which are critical for butanol recovery through vapor adsorption (Cao et al., 2015).

It is possible to treat $\mathrm{AC}$ to alter the surface functional groups present. For example, acid modification can increase the amount of acidic groups present, making AC ideal for the uptake of heavy metals or bases. Meanwhile, base modification will increase conjugated pi electron systems, making it ideal for uptake of aromatic organic acids (Yin et al., 2007). The performance of $\mathrm{AC}$ in most applications is related to its pore structure, specific surface area, and surface functional groups, with modification of its properties being the target of treatment (Soudani et al., 2013). Butanol is neutral with a hydroxyl group. According to the hydrogen-bonding interaction, we hypothesized that butanol adsorption capacity could be increased by generating carboxyl and hydroxyl groups on the surface of the active carbons, which would potentially form hydrogenbonding interaction with butanol. The aim of this study was to investigate the effects of nitric acid hydrothermal modification on the butanol adsorption /desorption activity of AC.

\subsection{Materials and methods}

\subsection{Materials}

$\mathrm{HNO}_{3}$, butanol, hydrochloride acid, sodium hydroxide, and ethanol were purchased from Thermo Fisher Scientific Inc. All of these chemicals were analytical grade. Commercial AC Sabre Series CR2050C-75 (unmodified AC) was donated by Carbon Resources. Several types of modified $\mathrm{AC}$ were generated by reacting the commercial $\mathrm{AC}$ at different concentrations of $\mathrm{HNO}_{3}$.

\subsection{Methods}

\subsubsection{Modification of AC}

The commercial AC was washed by boiling water with a Soxhlet extractor for $2 \mathrm{~h}$. The wet $\mathrm{AC}$ was dried at $105^{\circ} \mathrm{C}$ for $24 \mathrm{~h}$. Five $\mathrm{g}$ of the dried $\mathrm{AC}$ was reacted with $30 \mathrm{ml} \mathrm{HNO}_{3}$ at $2 \mathrm{M}$, 
$4 \mathrm{M}$ and $6 \mathrm{M}$ concentrations in a sealed PTFE reactor $(50 \mathrm{ml})$ at $120^{\circ} \mathrm{C}$ for $1 \mathrm{~h}$. After reaction, the reactant was cooled and filtered, then washed with deionized water under vacuum filtration until the $\mathrm{pH}$ value of the permeate was $\sim 7$. Finally, the washed $\mathrm{AC}$ was dried in a vacuum oven at $105{ }^{\circ} \mathrm{C}$ overnight. Then the dried $\mathrm{AC}$ was ground and run through a sieve, and grains falling within US mesh sizes 50-100 were used as absorbents.

\subsubsection{Analytical methods for absorbents}

Isotherm adsorption of $\mathrm{N}_{2}$ was carried out using an ASAP 2010 Micropore Analyzer. The total pore volume was determined at relative pressure $0.995 \mathrm{P}_{0}$, and the specific surface area was calculated from the BET method. The micropore and mesopore volume and the pore size distribution were determined by the density functional theory (DFT) for samples based on the $\mathrm{N}_{2}$ isotherm adsorption data.

Temperature-programmed desorption (TPD) was performed using a Micrometrics Autochem II Chemisorption Analyzer to investigate the oxygen content of these four AC samples. The carbon sample $(0.1 \mathrm{~g})$ was placed in a U-shaped quartz tube inside an electrical furnace and heated at $10{ }^{\circ} \mathrm{C} / \mathrm{min}$ up to $1000{ }^{\circ} \mathrm{C}$ using a constant flow rate of helium (the flow rate of the vapor, carrier, and reference were set at 0,60 , and $60 \mathrm{~cm}^{3} / \mathrm{min}$ respectively). The thermal conductivity detector (TCD) signals were monitored during the thermal analysis, and the corresponding TCD spectra was obtained.

\subsubsection{Gas Chromatography Mass Spectrometer (GC-MS) analytical procedure}

GC-MS was applied to analyze the outlet of the sample tube. Chromatographic analysis was performed in a Shimadzu series GC-MS (Shimadzu Corporation, USA) equipped with an RXI capillary column $(30 \mathrm{~m} \times 0.15 \mu \mathrm{m} \times 15 \mathrm{~mm})$. The initial temperature $\left(40{ }^{\circ} \mathrm{C}\right)$ was held for 1 min and then raised to $200{ }^{\circ} \mathrm{C}$ at a rate of $45^{\circ} \mathrm{C} / \mathrm{min}$. All samples were injected in split mode. The 
129 injection temperature was $150^{\circ} \mathrm{C}$. The mass spectrometer was operated in EI mode. Mass spectra 130 were acquired in full scan mode with repetitive scanning from $45 \mathrm{~m} / \mathrm{z}$ to $500 \mathrm{~m} / \mathrm{z}$ in $0.25 \mathrm{~s}$. Ion

131 source temperature was $250^{\circ} \mathrm{C}$.

\subsubsection{Dynamic adsorption and regeneration experiments}

The Micrometrics Autochem II Chemisorption Analyzer, connected to the Shimadzu GC-

MS, was also employed to investigate butanol adsorption and desorption on different absorbents.

Fig. 1 shows the schematic diagram of the adsorption system used for testing the adsorbents. The

136 flow rate of the vapor, carrier, and reference were set at 5,5 , and $10 \mathrm{~cm}^{3} / \mathrm{min}$, respectively.

137 Experiments were performed using helium as carrier gas, assuming that helium does not interfere

138 with butanol adsorption on AC (Cao et al., 2015). Pure butanol was heated to $50{ }^{\circ} \mathrm{C}$ and sparged

139 with helium at $5 \mathrm{~cm}^{3} / \mathrm{min}$. The gas outflow passed through the sample tube with carrier gas at 5

$140 \mathrm{~cm}^{3} / \mathrm{min}$. The butanol from the outflow was adsorbed by the loaded AC, and what remained

141 passed through the analysis chamber and then into the gas chromatograph. The reference

142 chamber recorded the TCD readings and ploted it against time. The GC-MS recorded the

143 intensity of the signal produced by the adsorbate as a function of time approximately once every

$14410.5 \mathrm{~min}$, and the integral of the curve provided the volume of adsorbate present after adsorption.

145 At least 20 data points were obtained by the GC-MS over the course of the analysis.

146 For regeneration, the TPD process pre-programmed into the Micromeritics analyzer was

147 used. The flow rate of the vapor, carrier, and reference were set at 0,10 , and $10 \mathrm{~cm}^{3} / \mathrm{min}$,

148 respectively. The temperature ramp was set at $15{ }^{\circ} \mathrm{C} / \mathrm{min}$, starting from $25^{\circ} \mathrm{C}$ to the set

149 temperature with a $1 \mathrm{~h}$ end temperature hold.

\section{$150 \quad$ 2.2.5 Butanol quantification}

To test the impact of surface modifications on the adsorption and desorption capacities of 
152 AC, a standard curve using a GC-MS was created as described previously (Cao et al., 2015).

153 Ethanol was used as solvent to prepare different concentrations of butanol (1.0, 5.0, 10.0, 20.0, $15430.0,50.0,60.0,75.0,93.0,170.0,235.0$, and $290.0 \mathrm{mg} / \mathrm{ml}$ ) which were analyzed in a Shimadzu

155 GC-MS to generate a standard curve that was subsequently used to measure butanol levels from 156 the outlet of the sample tube.

157 To quantify butanol vapor that was not adsorbed onto the adsorbent from the packed 158 column, $0.5 \mathrm{ml}$ of the outlet stream exiting the adsorption column was injected into GC-MS.

159 Since the GC-MS needed time to cool down, the outlet of the sample tube was measured every 16010.5 minutes. Determination of the outlet butanol vapor concentration as a function of time 161 allowed us to determine the breakthrough curve and experimentally calculate the dynamic 162 adsorption capacity of the packed column for each experiment. The adsorbed amounts were 163 calculated with the following equation:

164

$Q=\frac{M_{\text {adsorption }}}{W}=\frac{T_{q} C_{i} F_{A}}{W}$

The time $\mathrm{T}_{\mathrm{q}}$ is estimated according to the equation (2):

$$
T_{q}=\int\left(1-\frac{C_{O}}{C_{i}}\right) d t
$$

Where $\mathrm{Q}$ is the adsorbed amount $\left(\mathrm{mg} \mathrm{mg}^{-1}\right)$; $\mathrm{M}_{\text {adsorption }}$ is the mass of butanol absorbed

$168(\mathrm{mg}) ; \mathrm{F}_{\mathrm{A}}$ is the volumetric flow rate of the carrier gas $\left(\mathrm{ml} \mathrm{min}^{-1}\right)$; $\mathrm{W}$ is the net weight of 169 adsorbent $(\mathrm{mg}) ; \mathrm{C}_{\mathrm{i}}$ represents the butanol concentration at the inlet $\left(\mu \mathrm{g} \mathrm{ml}^{-1}\right) ; \mathrm{C}_{\mathrm{o}}$ is the butanol 170 concentration at the outlet $\left(\mu \mathrm{g} \mathrm{ml}^{-1}\right)$.

\section{3. Results and Discussion}

\section{$172 \quad 3.1$ Physicochemical properties of active carbons}

Pore structure and surface area parameters were obtained by the $\mathrm{N}_{2}$ adsorption method,

174 while micropore volume was determined using the density functional theory (DFT). Fig. 2A 
175 shows the $\mathrm{N}_{2}$ adsorption/desorption isothermal curves of the four adsorbents. The isotherms were 176 similar for both the original $\mathrm{AC}$ and the $\mathrm{AC}$ treated with $2 \mathrm{M} \mathrm{HNO}_{3}$, but when $\mathrm{AC}$ was treated 177 with higher $\mathrm{HNO}_{3}$ concentrations (4 and $6 \mathrm{M}$ ), $\mathrm{N}_{2}$ uptake increased. Table 1 shows that the BET 178 surface areas were larger (1486 and $1277 \mathrm{~m}^{2} \mathrm{~g}^{-1}$, respectively) for these latter treatments in 179 comparison to the original AC $\left(1157 \mathrm{~m}^{2} \mathrm{~g}^{-1}\right)$. Table 1 also shows that the pore structures were 180 affected by the higher $\mathrm{HNO}_{3}$ concentrations. The total pore volumes of the modified AC 181 increased 0.24 and $0.13 \mathrm{~cm}^{3} \mathrm{~g}^{-1}$ for the $4 \mathrm{M}$ and $6 \mathrm{M} \mathrm{HNO}_{3}$ modifications, respectively, in

182 183 184 185 186 187 188 189 190 191 192 193 194 195 196

comparison to untreated AC. Total pore volume for the $2 \mathrm{M} \mathrm{HNO}_{3}$ treatment was similar to the control. Formation of new pores or opening of inaccessible pores are two possible explanations for the increased BET surface areas (Silva et al., 2009).

The nitric acid hydrothermal treatment increased the micropore volumes of modified ACs from $0.39 \mathrm{~cm}^{3} \mathrm{~g}^{-1}$ in $\mathrm{AC}$ to $0.43,0.49$ and $0.43 \mathrm{~cm}^{3} \mathrm{~g}^{-1}$ by using 2,4 and $6 \mathrm{M} \mathrm{HNO}_{3}$ modifications, respectively. Increased micropore volume and BET surface area both contributed to enhanced accessibility to the inner part of the micropores by defect creation and/or opening of blocked micropores. Although the micropore volume increased slightly, the total pore volume of the $2 \mathrm{M} \mathrm{HNO}_{3}$ modified AC was similar to the control $\left(0.72 \mathrm{vs} 0.73 \mathrm{~cm}^{3} \mathrm{~g}^{-1}\right)$, perhaps because this treatment caused mesopore volume to drop (from 0.27 to $0.24 \mathrm{~cm}^{3} \mathrm{~g}^{-1}$ ). This may have been caused by intensive erosion of mesopore walls by $\mathrm{HNO}_{3}$, resulting in partial destruction or collapse of the porous structure (Soudani et al., 2013; Wang et al., 2009; Yin et al., 2007). Some of the mesopore may have changed into micropore. Table 1 shows that the average pore diameter of the $\mathrm{AC}$ decreased from 2.49 into $2.36 \mathrm{~nm}$ following treatment with $2 \mathrm{M} \mathrm{HNO}_{3}$. In addition, the oxygen containing groups introduced by $\mathrm{HNO}_{3}$ modification were probably fixed at the 
197 active sites at the entrance of the mesopores (Khelifi et al., 2010). These oxygen containing 198 groups could hinder access to the pores.

199 By contrast, mesopore volume increased greatly for samples modified by 4 and $6 \mathrm{M}$ $200 \mathrm{HNO}_{3}$ (Table 1). As is shown in Fig. 2B, DFT model simulation results according to the nitrogen 201 adsorption/desorption curve indicate that the volume of pores between $2 \mathrm{~nm}$ and $50 \mathrm{~nm}$ were 202 increased from 0.27 to $0.39\left(4 \mathrm{M} \mathrm{HNO}_{3}\right)$ and $0.36 \mathrm{~cm}^{3} \mathrm{~g}^{-1}\left(6 \mathrm{M} \mathrm{HNO}_{3}\right)$, respectively. Higher 203 concentrations of $\mathrm{HNO}_{3}$ reacted much more strongly, causing more robust oxidation and etching 204 of the carbon matrix of AC, and generating additional micropores and mesopores by eroding 205 carbon walls via strong oxidation. Widening of micropores into mesopores also may have 206 contributed to the greater increase in mesopores. This resulted in the average pore diameter of 207 the ACs modified by 4 and $6 \mathrm{M} \mathrm{HNO}_{3}$ increasing to 2.58 and $2.66 \mathrm{~nm}$, respectively (Table 1 ). In summary, $4 \mathrm{M} \mathrm{HNO}_{3}$ treatment of $\mathrm{AC}$ resulted in the largest changes in $\mathrm{AC}$ texture, 209 surface area, micropore volume, and total pore volume. This suggests that a proper concentration 210 of $\mathrm{HNO}_{3}$ can generate more micropores and mesopores. Due to erosion of reactive sites on the 211 AC, total pore volume increased at higher concentrations of oxidative acid (e.g. 4 and $6 \mathrm{M}$ $\left.212 \mathrm{HNO}_{3}\right)$. Temperature-programmed desorption (TPD) was employed to investigate the functional 214 groups generated by $\mathrm{HNO}_{3}$ modification. The carrier gas helium and the detected gases $\left(\mathrm{CO}, \mathrm{O}_{2}\right.$ 215 and $\mathrm{CO}_{2}$ ) have different thermal conductivities. TCD signals from the evolved gases were 216 recorded and the areas under the peak were proportional to the amount of gases produced. The 217 TCD readings were zeroed using carrier gas and reference gas at the beginning of each 218 measurement. 
Fig. 2C displays the TPD spectra arising from oxygenated groups released as CO and

$220 \mathrm{CO}_{2}$ from the surface of $\mathrm{AC}$ that had been hydrothermally treated with different concentration of

$221 \mathrm{HNO}_{3}$. The TPD profile measured for the untreated AC was also included. The quantity of

222 oxygenated groups released during treatment was directly related to the $\mathrm{HNO}_{3}$ concentration

223 used to treat AC. Generally, carboxylic functional groups decompose and release $\mathrm{H}_{2} \mathrm{O}$ at lower

224 temperatures $\left(100^{\circ} \mathrm{C}\right.$ to $\left.400{ }^{\circ} \mathrm{C}\right)$, while anhydride and lactone groups decompose at higher

225 temperatures $\left(427^{\circ} \mathrm{C}\right)$ (Marchon et al., 1988; Zhuang et al., 1994; Zielke et al., 1996). In this

226 study, the peaks formed between $400-1000{ }^{\circ} \mathrm{C}$ were assumed to be $\mathrm{CO}_{2}$ and $\mathrm{CO}$ (Figueiredo et al.,

227 1999), and the CO was possibly derived from the decomposition of phenols, ethers and

228 carbonyls/quinones (Langley et al., 2005; Ruta et al., 2008; Tribolet \& Kiwi-Minsker, 2005).

3.2 Adsorption of butanol on the adsorbents

\subsubsection{Adsorption of different concentrations of butanol on unmodified AC}

To observe the effects of butanol vapor concentration $(11.9,15.9,19.9,23.9$ and $31.9 \mu \mathrm{g}$

$232 \mathrm{ml}^{-1}$ ) on the breakthrough characteristic of AC, experiments were conducted at atmospheric

233 conditions and $25^{\circ} \mathrm{C}$. As shown in Fig. 3A, the breakthrough time considerably decreased from

234 about $85 \mathrm{~min}$ to less than $30 \mathrm{~min}$ as the butanol concentration increased from 11.9 to $31.9 \mu \mathrm{g} \mathrm{ml}^{-1}$.

235 The widely used Langmuir isotherm has found successful application in many real

236 adsorption processes and is expressed as:

237

$q_{e}=\frac{q_{m} B P_{e}}{1+B P_{e}}$

which can be rearranged to obtain a linear form

239

$$
\frac{P_{e}}{q_{e}}=\frac{P_{e}}{q_{m}}+\frac{1}{q_{m} B}
$$

where $\mathrm{q}_{\mathrm{m}}$ refers to the monolayer adsorption capacity, $\mathrm{q}_{\mathrm{e}}$ is amount of adsorption at 
constant.

A linearized plot of $\mathrm{P}_{\mathrm{e}} / \mathrm{q}_{\mathrm{e}}$ versus $\mathrm{q}_{\mathrm{e}}$ was obtained from the model shown in Fig. S1. The fit is good for unmodified AC with butanol vapor under the concentration ranges studied (correlation coefficient, $\mathrm{R}^{2}>0.988$ ). This indicates that the calculated maximum monolayer capacity $\mathrm{q}_{\mathrm{m}}$ of butanol vapor onto the unmodified AC is $359.7 \mathrm{mg} \mathrm{g}^{-1}$ and the Langmuir isotherm parameter $\mathrm{B}$ is $5.24 \mathrm{kPa}^{-1}$.

\subsubsection{Adsorption of butanol on the adsorbents at $25^{\circ} \mathrm{C}$}

Fig. 3B shows the breakthrough curves for $11.9 \mu \mathrm{g} \mathrm{ml}^{-1}$ butanol under atmospheric conditions and $25^{\circ} \mathrm{C}$ when adsorbed by the various AC samples. All samples had almost the same saturation time (158 min). The adsorption behavior of untreated AC and AC modified by 2 $\mathrm{M} \mathrm{HNO}_{3}$ were very similar, as the breakthrough curves almost overlapped. The breakthrough time $\left(\mathrm{C}_{\mathrm{o}} / \mathrm{C}_{\mathrm{i}}=0.05\right.$, which is defined as the time that the ratio of outlet to the inlet butanol concentration reaches 0.05$)$ for $2 \mathrm{M} \mathrm{HNO}_{3}$ modified $\mathrm{AC}$ was slightly lower ( $\left.88.5 \mathrm{~min}\right)$ than the unmodified AC (90.0 min). Values for the key adsorption parameters listed in Table 2 were within the margin of error for the control and the $2 \mathrm{M} \mathrm{HNO}_{3} \mathrm{AC}$ treatment, suggesting that it was not strong enough to change adsorption significantly. This is consistent with the relative lack of change in micropore, mesopore, and total pore volumes noted in Table 1.

On the other hand, after treatment of $\mathrm{AC}$ with higher concentrations of $\mathrm{HNO}_{3}$ (4 and $\left.6 \mathrm{M}\right)$, butanol breakthrough times were reduced to 75.0 and $58.0 \mathrm{~min}$, respectively. It can be observed (Fig. 3B) that the profile corresponding to the $4 \mathrm{M} \mathrm{HNO}_{3}$-modified $\mathrm{AC}$ was steeper than that of 6 $\mathrm{M} \mathrm{HNO}_{3}$-modified $\mathrm{AC}$, which implies a slower butanol adsorption rate for the latter. The AC modified by $4 \mathrm{M} \mathrm{HNO}_{3}$ had a greater total pore volume $\left(+0.11 \mathrm{~cm}^{3} \mathrm{~g}^{-1}\right)$ and a higher percentage of micropores compared to mesopores than $6 \mathrm{M} \mathrm{HNO}_{3}$-modified AC. Oxygen-containing 
272

273

274

275

276

277

278

279

280

281

functional generated during $\mathrm{HNO}_{3}$ treatment could also cause resistance to butanol diffusion into micropores, making it butanol breakthrough more rapid. Thus the order of butanol breakthrough was $6 \mathrm{M} \mathrm{HNO}_{3}<4 \mathrm{M} \mathrm{HNO}_{3}<2 \mathrm{M} \mathrm{HNO}_{3}<$ unmodified for these $\mathrm{AC}$ samples.

It is well-known that both the porous structure and the surface chemistry of AC are important factors affecting adsorption of different compounds. Increasing the surface area of sorbents will generally lead to improved adsorption, but the effects of functional surface groups on the adsorptive characteristics of ACs is closely related to the chemical nature of the adsorbates. As can be seen from Fig. S2, the water contact angle for unmodified AC was $99^{\circ}$, and it decreased to $35^{\circ}$ after modification with $2 \mathrm{M} \mathrm{HNO}_{3}$. Water contact angles could not be measured on the surface of the 4 and $6 \mathrm{M} \mathrm{HNO}_{3}$-modified ACs since water droplets spread out too rapidly. Conversely, butanol spread very rapidly on the surface of the unmodified-AC, while butanol contact angles of $13^{\circ}, 16^{\circ}$, and $17^{\circ}$ were measured for AC treated with 2,4 , and $6 \mathrm{M}$ $\mathrm{HNO}_{3}$, respectfully. This indicates that $\mathrm{HNO}_{3}$ modification changed $\mathrm{AC}$ from a hydrophobic into hydrophilic material, and the higher $\mathrm{HNO}_{3}$ concentration resulted the higher surface hydrophilicity. Butanol has higher affinity for hydrophobic active carbons than hydrophilic active carbon. Hence, the slightly decreased butanol adsorption was partially due to the increased oxygen functional groups, which decreased the affinity of butanol.

Although the $\mathrm{AC}$ modified by $4 \mathrm{M} \mathrm{HNO}_{3}$ had largest BET surface area and highest total pore volume, it had the lowest dynamic saturate adsorption capacity (236.8 $\mathrm{mg} \mathrm{g}^{-1}$, Table 2$)$. The the kinetic diameter of butanol is $0.5 \mathrm{~nm}$ (Borjigin et al., 2012), and the high proportion of micropores (smaller than $2 \mathrm{~nm}$ ) in the AC modified by $4 \mathrm{M} \mathrm{HNO}_{3}\left(0.49 \mathrm{~cm}^{3} \mathrm{~g}^{-1}\right)$ provided a more stable environment to store butanol molecules. However, partial micropores were not able to adsorb the butanol molecules effectively since they were covered with oxygen-containing 
functional groups, which repelled the butanol molecules. Therefore, adsorption of butanol is not only dependent on the BET surface but also on the surface functional groups.

\subsubsection{Adsorption of butanol on the adsorbents at $30{ }^{\circ} \mathrm{C}$}

Fig. 3C shows the breakthrough curves for butanol under atmospheric conditions and $30{ }^{\circ} \mathrm{C}$. The breakthrough time of these four adsorbents was much lower compared with adsorption at $25^{\circ} \mathrm{C}$. Increasing the adsorption temperature decreased both breakthrough time and total adsorption. The unmodified AC still had the highest adsorption capacity $\left(170.0 \mathrm{mg} \mathrm{g}^{-1}\right.$,

Table 3), while the $4 \mathrm{M} \mathrm{HNO}_{3}$-modified AC had the lowest adsorption capacity (139.4 $\mathrm{mg} \mathrm{g}^{-1}$, Table 3). The adsorption capacity of the $2 \mathrm{M} \mathrm{HNO}_{3}$-modified $\mathrm{AC}\left(168.2 \mathrm{mg} \mathrm{g}^{-1}\right)$ was statistically similar to the untreated control, but higher than the $6 \mathrm{M} \mathrm{HNO}_{3}$-modified $\mathrm{AC}\left(163.8 \mathrm{mg} \mathrm{g}^{-1}\right)$. Thus the trends in adsorption behavior were similar for both 25 and $30^{\circ} \mathrm{C}$.

Higher adsorption temperatures were also investigated for the unmodified AC. Fig. S2 shows the breakthrough curve shifted further to the left as the temperature was increased to $35^{\circ} \mathrm{C}$, indicating an early saturation of the unmodified AC. Therefore, lower temperature seems to have higher adsorption for the butanol vapor. Since both higher and lower adsorption temperatures require much more energy than the room temperature $25^{\circ} \mathrm{C}$, the optimal adsorption temperature for butanol vapor is $25^{\circ} \mathrm{C}$.

\subsection{Regeneration of the adsorbent}

Heating was used to recover butanol and regenerate adsorbent from saturated AC samples. Fig. 4A shows the TPD of butanol saturated, unmodified AC at 110,130 , and $150{ }^{\circ} \mathrm{C}$. The TCD signal shows that butanol desorption was positively correlated with regeneration temperature, with the highest amount of butanol evolved at $150{ }^{\circ} \mathrm{C}$. In a subsequent adsorption cycle with the unmodified $\mathrm{AC}$ that had been regenerated at $130^{\circ} \mathrm{C}$, we observed a decrease in adsorption 
ability compared to fresh, unmodified AC (Fig. 4B). In this case the breakthrough time decreased from 95 to $50 \mathrm{~min}$, and the saturation time decreased from 158 to $126.5 \mathrm{~min}$. This indicates that $130{ }^{\circ} \mathrm{C}$ is not high enough to remove all of the adsorbed butanol vapor.

In a separate test we used a regeneration temperature of $150{ }^{\circ} \mathrm{C}$ to assess adsorption ability of unmodified AC for four cycles of adsorption/desorption. As is shown in the Fig. 5A, the breakthrough curves for the four cycles were identical, indicating that $150{ }^{\circ} \mathrm{C}$ is an appropriate desorption temperature for butanol saturated AC. The almost overlapped adsorptions mean that the unmodified $\mathrm{AC}$ has non-changed adsorption ability after heating regeneration at $150^{\circ} \mathrm{C}$.

To investigate the influence of oxidation on repeated adsorption/desorption cycles, AC modified with $6 \mathrm{M} \mathrm{HNO}_{3}$ was evaluated. The outlet was monitored by TCD and GC-MS during desorption. As shown in Fig. 5B, the adsorption capacity appeared to decrease after the first adsorption and desorption round, but was stable for the second to fourth cycles. From the TCD signals (Fig. 6) for the desorptions, it can be concluded that the adsorption capacities for butanol were almost the same for the second to fourth cycles. However, the breakthrough curve (Fig. 5B) for the first adsorption indicates that it has loaded more butanol than the subsequent adsorption cycles. We hypothesize that surface oxides reacted with butanol and formed new functional groups on the surface in the first round, which partially blocked butanol chemical adsorption sites for cycles two though four.

Fig. 4SA is the GC-MS profile of the outlet at $100{ }^{\circ} \mathrm{C}$ for the first regeneration. Besides the butanol peak, there were four peaks. According to the MS profiles (Fig. 4SB) and a similarity search in the GC-MS standard library, peak 1 was 1-butene, peak 2 was butane, peak 3 was butanol, peak 4 was formic acid butyl ester, and peak 5 was n-Butyl ether. The mass spectral 
334 similarities were $98 \%, 98 \%, 98 \%, 98 \%$, and 94\%, respectively. Thus, it can be inferred that the

335 modified AC catalytically reacted with butanol. The exact mechanism of the reaction cannot be 336 explained at the present stage of investigation. A detailed analysis will be needed in the future.

\section{4. Conclusion}

Hydrothermal modification with $4 \mathrm{M} \mathrm{HNO}_{3}$ increased BET surface area by $329 \mathrm{~m}^{2} \mathrm{~g}^{-1}$,

339 micropore volume by $0.10 \mathrm{~cm}^{3} \mathrm{~g}^{-1}$, and mesopore volume by $0.12 \mathrm{~cm}^{3} \mathrm{~g}^{-1}$. However, the

340 adsorption capacity (dynamic saturate) decreased from 255.8 to $236.6 \mathrm{mg} \mathrm{g}^{-1}$. The oxygen-

341 containing functional groups generated by $\mathrm{HNO}_{3}$ hydrothermal treatment decreased the butanol

342 adsorption ability of the AC. Overall, the adsorption capacity is not only related to the pore

343 structure but also the surface functional groups. The butanol absorbed by the modified AC cannot

344 be fully recovered after the first adsorption because it partially reacts with the functional groups

345 on the surface.

\section{Acknowledgements}

347 This research was funded by following projects: 1) "Development of high value carbon based

348 adsorbents from thermochemically produced biochar" USDA-NIFA 2011-67009-20030 through

349 the USDA-NIFA Agriculture and Food Research Initiative Sustainable Bioenergy Program which

350 funded the Micropore analyzer and instruments for modifying AC; 2) NSF EPSCoR Track II

351 Dakota BioCon center (National Science Foundation/EPSCoR Award No. 1330842) supported

352 Mr. Cao Yuhe for his PhD study and GC-MS instrument; 3) DOE Sun Grant Concept Project

353 "Developing Gas Stripping - Adsorption/Desorption Separation Processes based on Porous

354 Carbon Adsorbents for Biofuel Purification from Bioreactors" (North Central Sun Grant Award

355 No. 1300478) supported upgrading the Chemical Adsorption Analyzer. 


\section{References}

1. Bellido, C., Loureiro Pinto, M., Coca, M., Gonzalez-Benito, G., Garcia-Cubero, M.T. 2014. Acetone-butanol-ethanol (ABE) production by Clostridium beijerinckii from wheat straw hydrolysates: efficient use of penta and hexa carbohydrates. Bioresour. Technol., 167, 198-205.

2. Borjigin, T., Sun, F., Zhang, J., Cai, K., Ren, H., Zhu, G. 2012. A microporous metalorganic framework with high stability for GC separation of alcohols from water. Chem. Commun., 48, 7613-5.

3. Cao, Y., Wang, K., Wang, X., Gu, Z., Gibbons, W., Vu, H. 2015. Butanol vapor adsorption behavior on active carbons and zeolite crystal. Appl. Surf. Sci., 349, 1-7.

4. Cousin Saint Remi, J., Baron, G., Denayer, J. 2012. Adsorptive separations for the recovery and purification of biobutanol. Adsorption, 18, 367-373.

5. de Vrije, T., Budde, M., van der Wal, H., Claassen, P.A., Lopez-Contreras, A.M. 2013. "In situ" removal of isopropanol, butanol and ethanol from fermentation broth by gas stripping. Bioresour. Technol., 137, 153-9.

6. Figueiredo, J.L., Pereira, M.F.R., Freitas, M.M.A., Órfão, J.J.M. 1999. Modification of the surface chemistry of activated carbons. Carbon, 37, 1379-1389.

7. Gottumukkala, L.D., Parameswaran, B., Valappil, S.K., Mathiyazhakan, K., Pandey, A., Sukumaran, R.K. 2013. Biobutanol production from rice straw by a non acetone producing Clostridium sporogenes BE01. Bioresour. Technol., 145, 182-7.

8. Ha, S.H., Mai, N.L., Koo, Y.-M. 2010. Butanol recovery from aqueous solution into ionic liquids by liquid-liquid extraction. Process Biochem., 45, 1899-1903.

9. Khelifi, A., Almazán-Almazán, M.C., Pérez-Mendoza, M., Domingo-García, M., LópezDomingo, F.J., Temdrara, L., López-Garzón, F.J., Addoun, A. 2010. Influence of nitric acid concentration on the characteristics of active carbons obtained from a mineral coal. Fuel Process. Technol., 91, 1338-1344.

10. Kim, H.M., Wi, S.G., Jung, S., Song, Y., Bae, H.J. 2014. Efficient approach for bioethanol production from red seaweed Gelidium amansii. Bioresour. Technol., 175C, 128-134.

11. Kraemer, K., Harwardt, A., Bronneberg, R., Marquardt, W. 2011. Separation of butanol from acetone-butanol-ethanol fermentation by a hybrid extraction-distillation process. Comput. Chem. Eng., 35, 949-963.

12. Kujawski, J., Rozicka, A., Bryjak, M., Kujawski, W. 2014. Pervaporative removal of acetone, butanol and ethanol from binary and multicomponent aqueous mixtures. Sep. Purif. Technol., 132, 422-429.

13. Langley, L.A., Villanueva, D.E., Fairbrother, D.H. 2005. Quantification of Surface Oxides on Carbonaceous Materials. Chem. Mater., 18, 169-178.

14. Liao, Y.C., Lu, K.M., Li, S.Y. 2014. Process parameters for operating 1-butanol gas stripping in a fermentor. J. Biosci. Bioeng., 118, 558-64.

15. Lin, L., Cunshan, Z., Vittayapadung, S., Xiangqian, S., Mingdong, D. 2011. Opportunities and challenges for biodiesel fuel. Appl. Energ., 88, 1020-1031.

16. Luo, L., Ramirez, D., Rood, M.J., Grevillot, G., Hay, K.J., Thurston, D.L. 2006. Adsorption and electrothermal desorption of organic vapors using activated carbon adsorbents with novel morphologies. Carbon, 44, 2715-2723. 
17. Manickam, S., Arigela, V.N.D., Gogate, P.R. 2014. Intensification of synthesis of biodiesel from palm oil using multiple frequency ultrasonic flow cell. Fuel Process. Technol., 128, 388-393.

18. Marchon, B., Carrazza, J., Heinemann, H., Somorjai, G.A. 1988. TPD and XPS studies of $\mathrm{O} 2, \mathrm{CO} 2$, and $\mathrm{H} 2 \mathrm{O}$ adsorption on clean polycrystalline graphite. Carbon, 26, 507-514.

19. Oudshoorn, A., van der Wielen, L.A.M., Straathof, A.J.J. 2009a. Adsorption equilibria of bio-based butanol solutions using zeolite. Biochem. Eng. J., 48, 99-103.

20. Oudshoorn, A., van der Wielen, L.A.M., Straathof, A.J.J. 2009b. Assessment of Options for Selective 1-Butanol Recovery from Aqueous Solution. Ind. Eng. Chem. Res., 48, 7325-7336.

21. Plaza, A., Merlet, G., Hasanoglu, A., Isaacs, M., Sanchez, J., Romero, J. 2013. Separation of butanol from $\mathrm{ABE}$ mixtures by sweep gas pervaporation using a supported gelled ionic liquid membrane: Analysis of transport phenomena and selectivity. J. Membr. Sci., 444, 201-212.

22. Ruta, M., Semagina, N., Kiwi-Minsker, L. 2008. Monodispersed Pd Nanoparticles for Acetylene Selective Hydrogenation: Particle Size and Support Effects. J. Phys. Chem. C, 112, 13635-13641.

23. Saint Remi, J.C., Remy, T., Van Hunskerken, V., van de Perre, S., Duerinck, T., Maes, M., De Vos, D., Gobechiya, E., Kirschhock, C.E., Baron, G.V., Denayer, J.F. 2011. Biobutanol separation with the metal-organic framework ZIF-8. ChemSusChem, 4, 10747.

24. Setlhaku, M., Heitmann, S., Gorak, A., Wichmann, R. 2013. Investigation of gas stripping and pervaporation for improved feasibility of two-stage butanol production process. Bioresour. Technol., 136, 102-8.

25. Silva, A.M.T., Machado, B.F., Figueiredo, J.L., Faria, J.L. 2009. Controlling the surface chemistry of carbon xerogels using HNO3-hydrothermal oxidation. Carbon, 47, 16701679.

26. Soudani, N., Souissi-najar, S., Ouederni, A. 2013. Influence of Nitric Acid Concentration on Characteristics of Olive Stone Based Activated Carbon. Chin. J. Chem. Eng., 21, 1425-1430.

27. Subrenat, A., Le Cloirec, P. 2004. Adsorption onto Activated Carbon Cloths and Electrothermal Regeneration: Its Potential Industrial Applications. J. Environ. Eng., 130, 249-257.

28. Tribolet, P., Kiwi-Minsker, L. 2005. Palladium on carbon nanofibers grown on metallic filters as novel structured catalyst. Catal. Today, 105, 337-343.

29. Wang, Q., Liang, X., Qiao, W., Liu, C., Liu, X., Zhang, R., Ling, L. 2009. Modification of polystyrene-based activated carbon spheres to improve adsorption of dibenzothiophene. Appl. Surf. Sci., 255, 3499-3506.

30. Xue, C., Zhao, X.Q., Liu, C.G., Chen, L.J., Bai, F.W. 2013. Prospective and development of butanol as an advanced biofuel. Biotechnol. Adv., 31, 1575-84.

31. Yen, H.W., Wang, Y.C. 2013. The enhancement of butanol production by in situ butanol removal using biodiesel extraction in the fermentation of ABE (acetone-butanol-ethanol). Bioresour. Technol., 145, 224-8.

32. Yin, C., Aroua, M., Daud, W. 2007. Review of modifications of activated carbon for enhancing contaminant uptakes from aqueous solutions. Sep. Purif. Technol., 52, 403-415. 
33. Zhao, X., Wei, L., Julson, J., Gu, Z., Cao, Y. 2015. Catalytic cracking of inedible camelina oils to hydrocarbon fuels over bifunctional Zn/ZSM-5 catalysts. Korean J. Chem. Eng., 32, 1528-1541.

34. Zhuang, Q.L., Kyotani, T., Tomita, A. 1994. The change of TPD pattern of O2-gasified carbon upon air exposure. Carbon, 32, 539-540.

35. Zielke, U., Hüttinger, K.J., Hoffman, W.P. 1996. Surface-oxidized carbon fibers: I. Surface structure and chemistry. Carbon, 34, 983-998. 


\section{Table caption}

Table 1 Surface area and pore structure parameters of the absorbents.

Table 2 Key adsorption parameters for butanol adsorption at $25{ }^{\circ} \mathrm{C}$.

Table 2 Key adsorption parameters for butanol adsorption at $30{ }^{\circ} \mathrm{C}$. 
Table 1 Surface area and pore structure parameters of the absorbents.

\begin{tabular}{cccccc}
\hline Sample \# & $\begin{array}{c}\mathrm{S}_{\mathrm{BET}}{ }^{\mathrm{a}} \\
\mathrm{m}^{2} \mathrm{~g}^{-1}\end{array}$ & $\begin{array}{c}\mathrm{V}_{\text {Total }}{ }^{\mathrm{b}} \\
\mathrm{cm}^{3} \mathrm{~g}^{-1}\end{array}$ & $\begin{array}{c}\mathrm{V}_{\text {Micro }}{ }^{\mathrm{c}} \\
\mathrm{cm}^{3} \mathrm{~g}^{-1}\end{array}$ & $\begin{array}{c}\mathrm{V}_{\text {Meso }}{ }^{\mathrm{d}} \\
\mathrm{cm}^{3} \mathrm{~g}^{-1}\end{array}$ & $\begin{array}{c}\mathrm{D}_{\text {Average }}{ }^{\mathrm{e}} \\
\mathrm{nm}\end{array}$ \\
\hline Unmodified AC & 1157 & 0.72 & 0.39 & 0.27 & 2.49 \\
2mol/L HNO $_{3}$ & 1236 & 0.73 & 0.43 & 0.24 & 2.36 \\
$4 \mathrm{~mol} / \mathrm{L} \mathrm{HNO}_{3}$ & 1486 & 0.96 & 0.49 & 0.39 & 2.58 \\
6mol/L HNO & 1277 & 0.85 & 0.43 & 0.36 & 2.66 \\
\hline
\end{tabular}

${ }^{\text {a }}$ BET (Brunauer-Emmett-Teller) surface area

${ }^{\mathrm{b}}$ Total pore volume, measured at $\mathrm{P} / \mathrm{P}_{0}=0.995$

${ }^{c}$ Micropore volume, based on density functional theory (DFT)

${ }^{\mathrm{d}}$ Mesopore volume, based on density functional theory (DFT)

${ }^{\mathrm{e}}$ Average pore diameter of absorbents, calculated by $4 \mathrm{~V}_{\text {Total }} / \mathrm{S}_{\mathrm{BET}}$ 
Table 2 Key adsorption parameters for butanol adsorption at $25{ }^{\circ} \mathrm{C}$.

\begin{tabular}{ccccc}
\hline Items & $\begin{array}{c}\text { Unmodified } \\
\mathrm{AC}\end{array}$ & $\begin{array}{c}2 \mathrm{M} \mathrm{HNO}_{3} \\
\text { treated AC }\end{array}$ & $\begin{array}{c}4 \mathrm{M} \mathrm{HNO}_{3} \\
\text { treated } \mathrm{AC}\end{array}$ & $\begin{array}{c}6 \mathrm{M} \mathrm{HNO}_{3} \\
\text { treated } \mathrm{AC}\end{array}$ \\
\hline $\mathrm{F}_{\mathrm{A}}{ }^{\mathrm{a}}\left(\mathrm{ml} \mathrm{min}^{-1}\right)$ & 10 & 10 & 10 & 10 \\
$\mathrm{~T}_{\mathrm{q}}{ }^{\mathrm{b}}(\mathrm{min})$ & $107.47 \pm 0.85$ & $106.51 \pm 0.97$ & $99.45 \pm 1.12$ & $102.56 \pm 1.01$ \\
$\mathrm{C}_{\mathrm{i}}{ }^{\mathrm{c}}\left(\mu \mathrm{g} \mathrm{ml}^{-1}\right)$ & 11.90 & 11.90 & 11.90 & 11.90 \\
$\mathrm{M}_{\text {adsorption }}{ }^{\mathrm{d}}(\mathrm{mg})$ & $12.79 \pm 0.10$ & $12.67 \pm 0.12$ & $11.83 \pm 0.13$ & $12.20 \pm 0.12$ \\
$\mathrm{~W}^{\mathrm{e}}(\mathrm{mg})$ & 50 & 50 & 50 & 50 \\
$\mathrm{Q}^{\mathrm{f}}\left(\mathrm{mg} \mathrm{g}^{-1}\right)$ & $255.8 \pm 2.0$ & $253.4 \pm 2.4$ & $236.6 \pm 2.6$ & $244.0 \pm 2.4$ \\
\hline
\end{tabular}

${ }^{\mathrm{a}}$ Volumetric flow rate of the carrier gas

${ }^{\mathrm{b}}$ Stoichiometric time determined from the breakthrough curve

${ }^{\mathrm{c}}$ Butanol concentration at the inlet

${ }^{\mathrm{d}}$ Mass of butanol adsorbed

${ }^{\mathrm{e}}$ Net weight of adsorbent

${ }^{\mathrm{f}}$ Dynamic adsorption capacity of the adsorbent 
Table 3 Key adsorption parameters for butanol adsorption at $30{ }^{\circ} \mathrm{C}$.

\begin{tabular}{ccccc}
\hline Items & $\begin{array}{c}\text { Unmodified } \\
\mathrm{AC}\end{array}$ & $\begin{array}{c}2 \mathrm{M} \mathrm{HNO}_{3} \\
\text { treated } \mathrm{AC}\end{array}$ & $\begin{array}{c}4 \mathrm{M} \mathrm{HNO}_{3} \\
\text { treated } \mathrm{AC}\end{array}$ & $\begin{array}{c}6 \mathrm{M} \mathrm{HNO}_{3} \\
\text { treated } \mathrm{AC}\end{array}$ \\
\hline $\mathrm{F}_{\mathrm{A}}{ }^{\mathrm{a}}\left(\mathrm{ml} \mathrm{min}^{-1}\right)$ & 10 & 10 & 10 & 10 \\
$\mathrm{~T}_{\mathrm{q}}{ }^{\mathrm{b}}(\mathrm{min})$ & $71.45 \pm 0.95$ & $70.71 \pm 1.03$ & $58.53 \pm 1.31$ & $68.82 \pm 1.10$ \\
$\mathrm{C}_{\mathrm{i}}{ }^{\mathrm{c}}\left(\mu \mathrm{m} \mathrm{ml}^{-1}\right)$ & 11.90 & 11.90 & 11.90 & 11.90 \\
$\mathrm{M}_{\text {adsorption }}{ }^{\mathrm{d}}(\mathrm{mg})$ & $8.50 \pm 0.11$ & $8.41 \pm 0.12$ & $6.97 \pm 0.16$ & $8.19 \pm 0.13$ \\
$\mathrm{~W}^{\mathrm{e}}(\mathrm{mg})$ & 50 & 50 & 50 & 50 \\
$\mathrm{Q}^{\mathrm{f}}\left(\mathrm{mg} \mathrm{g}^{-1}\right)$ & $170.0 \pm 2.2$ & $168.2 \pm 2.4$ & $139.4 \pm 3.2$ & $163.8 \pm 2.6$ \\
\hline
\end{tabular}

${ }^{a}$ Volumetric flow rate of the carrier gas

${ }^{\mathrm{b}}$ Stoichiometric time determined from the breakthrough curve

${ }^{\mathrm{c}}$ Butanol concentration at the inlet

${ }^{\mathrm{d}}$ Mass of butanol adsorbed

${ }^{\mathrm{e}}$ Net weight of adsorbent

${ }^{\mathrm{f}}$ Dynamic adsorption capacity of the adsorbent 


\section{Figure captions}

Fig. 1. Schematic diagram of the experimental adsorption system: 1, butanol bath; 2, sample tube; 3, vapor flow rate meter; 4, carrier flow rate meter; 5, reference flow rate meter; 6 , TCD detector; 7, GC-MS.

Fig. 2. (A) $\mathrm{N}_{2}$ isothermal adsorption/desorption on the absorbents; (B) DFT pore size distribution curves of the absorbents; (C) TCD signals for temperature-programmed desorption of AC samples.

Fig. 3 (A) Butanol adsorption capabilities of unmodified AC at different butanol concentrations; (B) Adsorption capabilities of different absorbents at $25^{\circ} \mathrm{C}$; (C) Adsorption capabilities of different absorbents at $30^{\circ} \mathrm{C}$.

Fig. 4. (A) Butanol desorption of unmodified AC at different temperatures; (B) Adsorption curves for fresh and regenerated (at $130{ }^{\circ} \mathrm{C}$ ) unmodified AC.

Fig. 5. (A) Repeated adsorption of butanol with unmodified AC; (B) Repeated adsorption of butanol with $6 \mathrm{M} \mathrm{HNO}_{3}$ modified AC.

Fig. 6. Butanol desorption of $6 \mathrm{M} \mathrm{HNO}_{3}$ modified AC. 


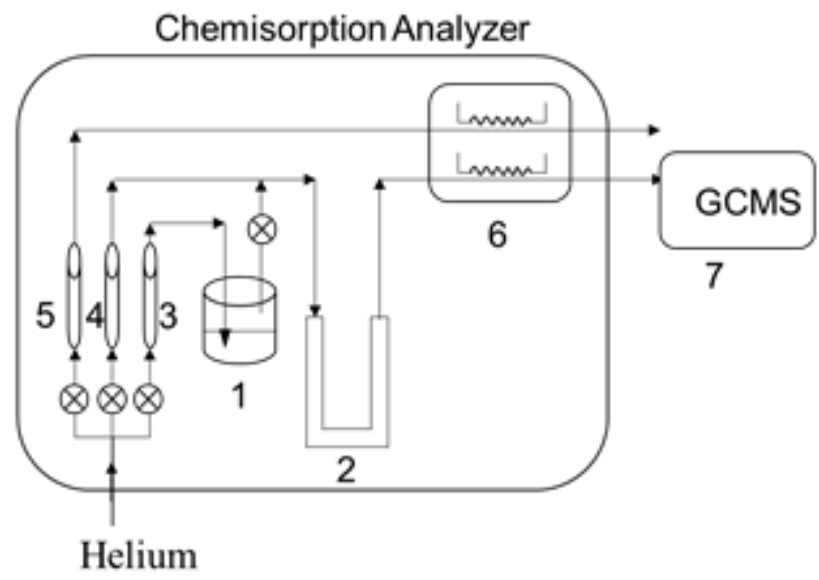

Fig. 1. Schematic diagram of the experimental adsorption system: 1, butanol bath; 2 , sample tube; 3 , vapor flow rate meter; 4 , carrier flow rate meter; 5 , reference flow rate meter; 6 , TCD detector; 7, GC-MS. 
A

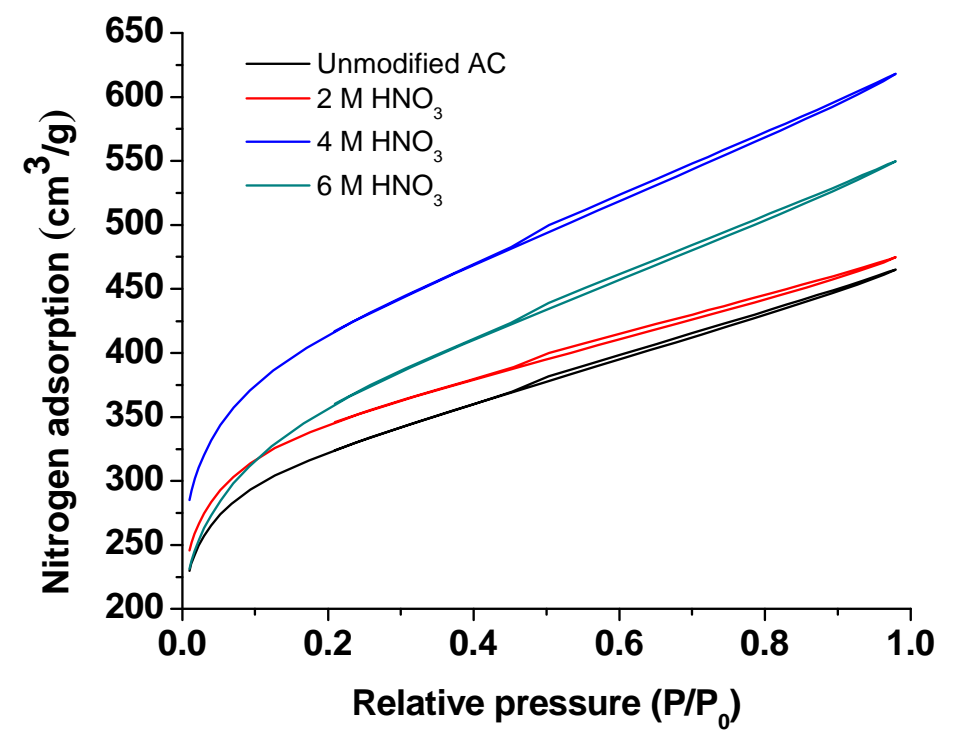

B

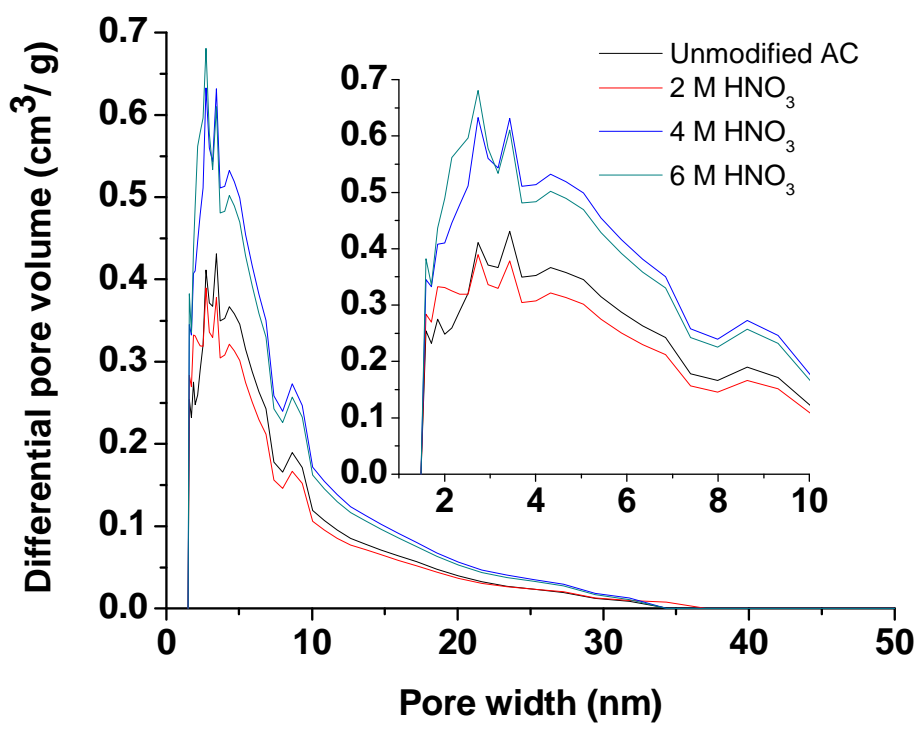

C 


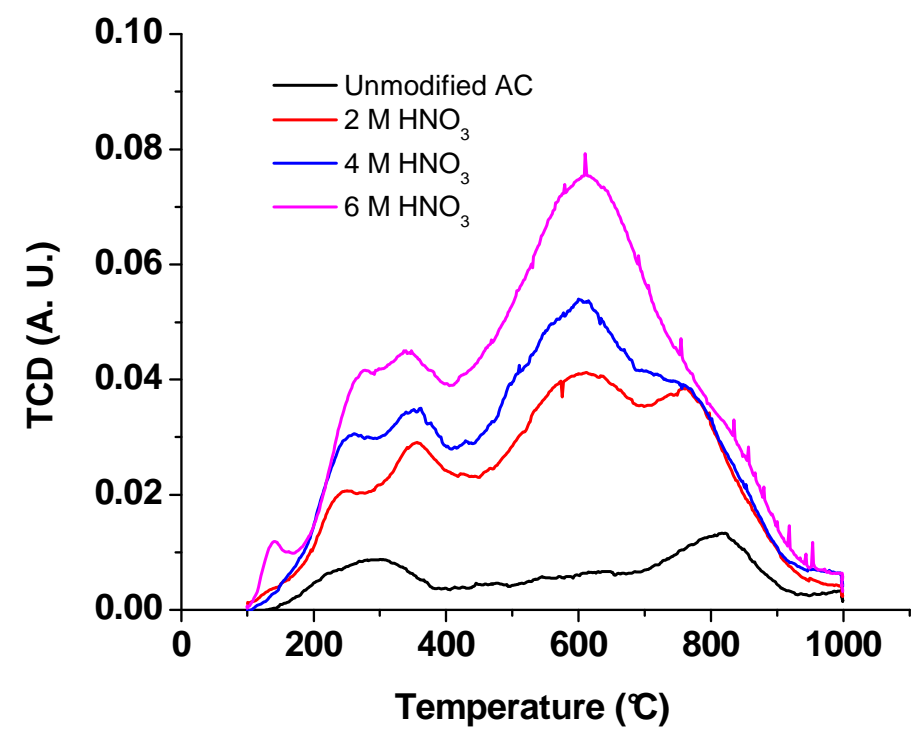

Fig. 2. (A) $\mathrm{N}_{2}$ isothermal adsorption/desorption on the absorbents; (B) DFT pore size distribution curves of the absorbents; (C) TCD signals for temperature-programmed desorption of AC samples. 
A

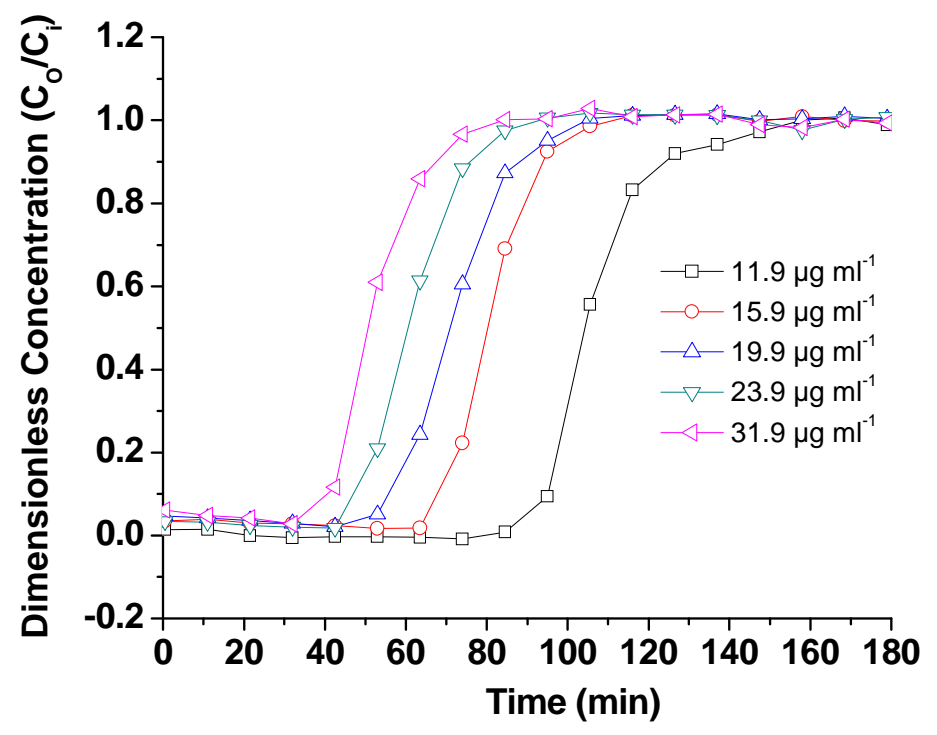

B

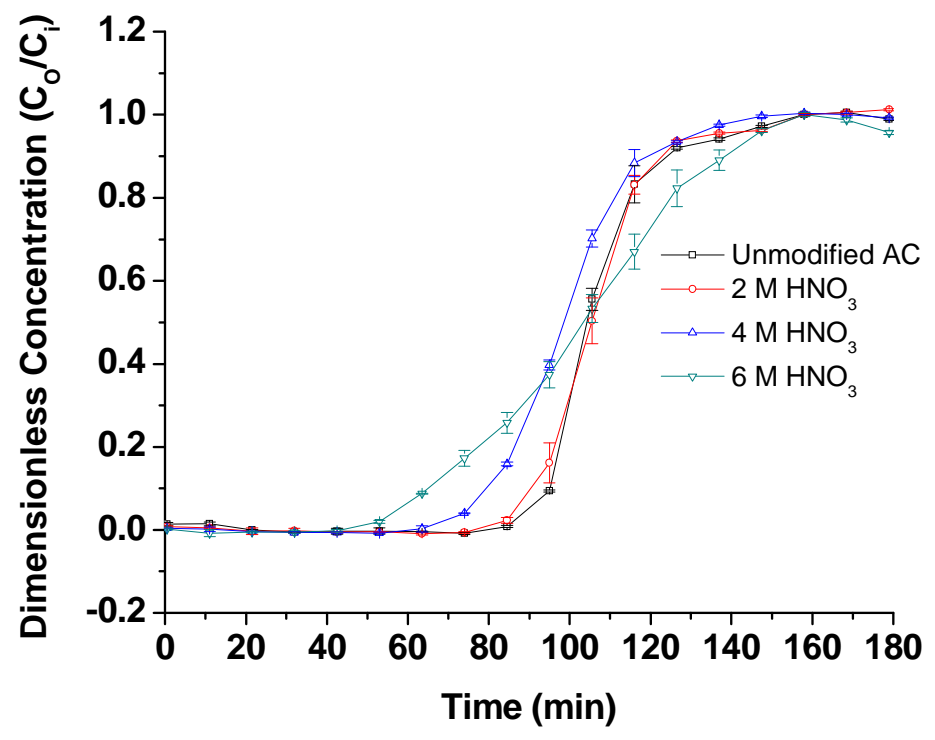

C 


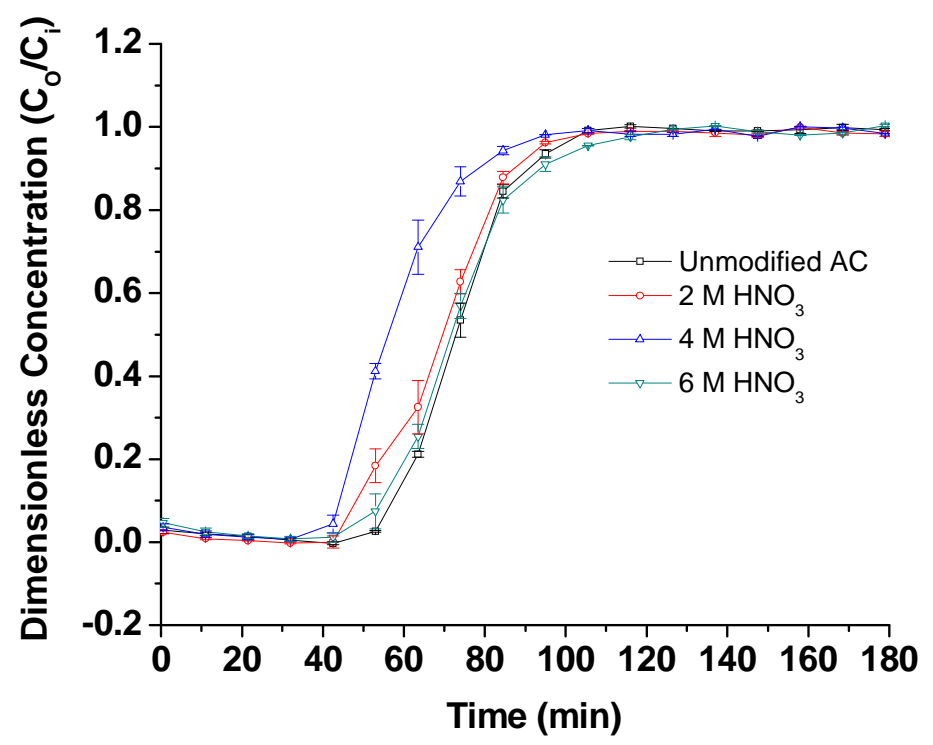

Fig. 3 (A) Butanol adsorption capabilities of unmodified AC at different butanol concentrations; (B) Adsorption capabilities of different absorbents at $25{ }^{\circ} \mathrm{C}$; (C) Adsorption capabilities of different absorbents at $30^{\circ} \mathrm{C}$. 
A

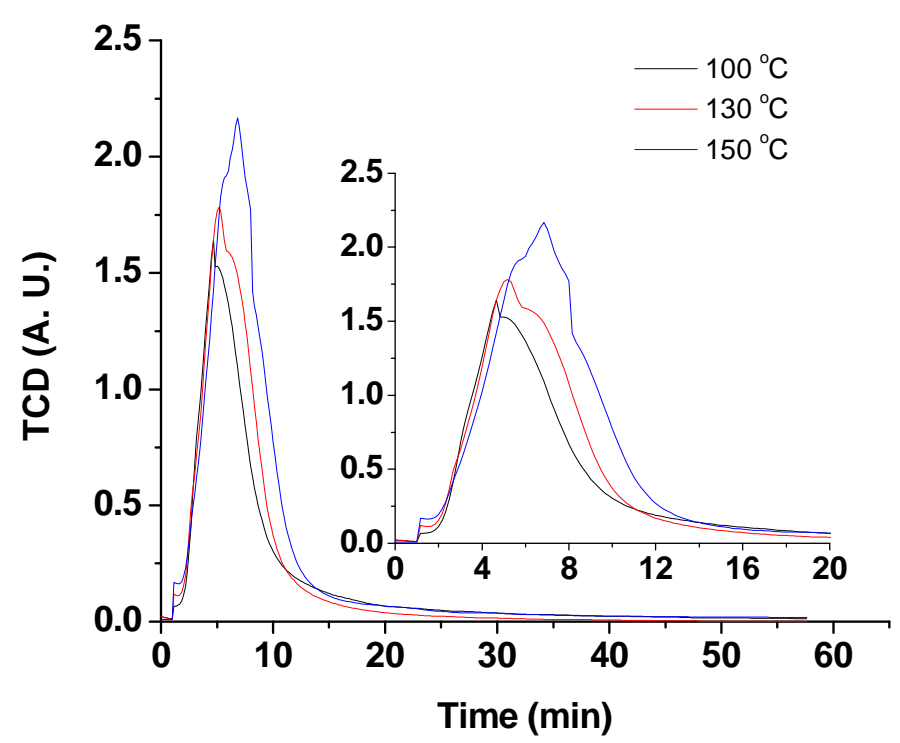

B

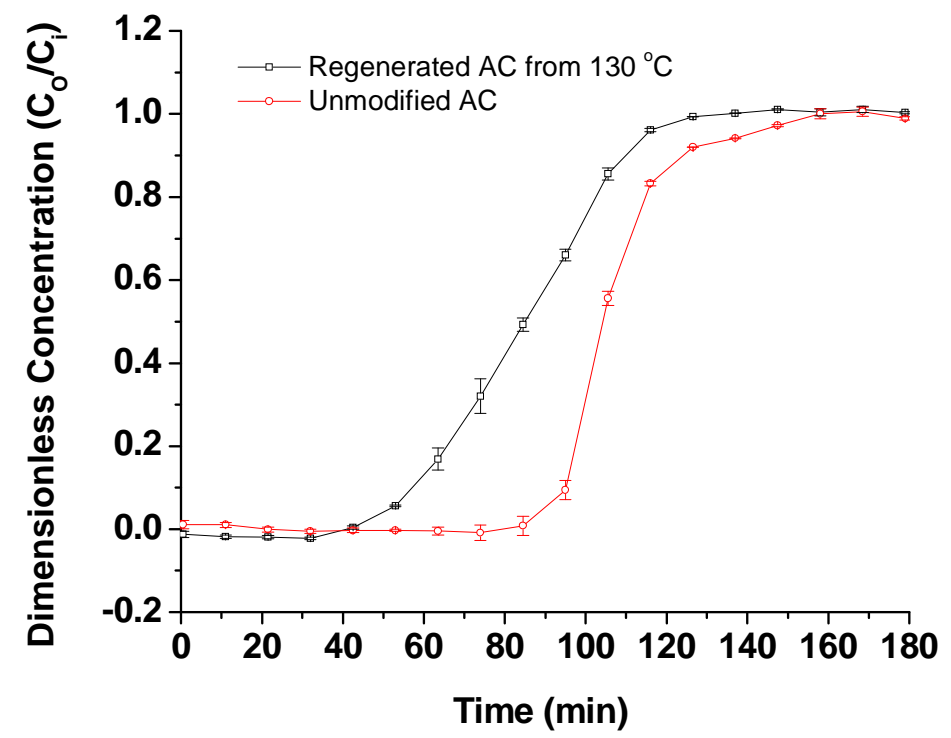

Fig. 4. (A) Butanol desorption of unmodified AC at different temperatures; (B) Adsorption curves for fresh and regenerated (at $130{ }^{\circ} \mathrm{C}$ ) unmodified AC. 
A

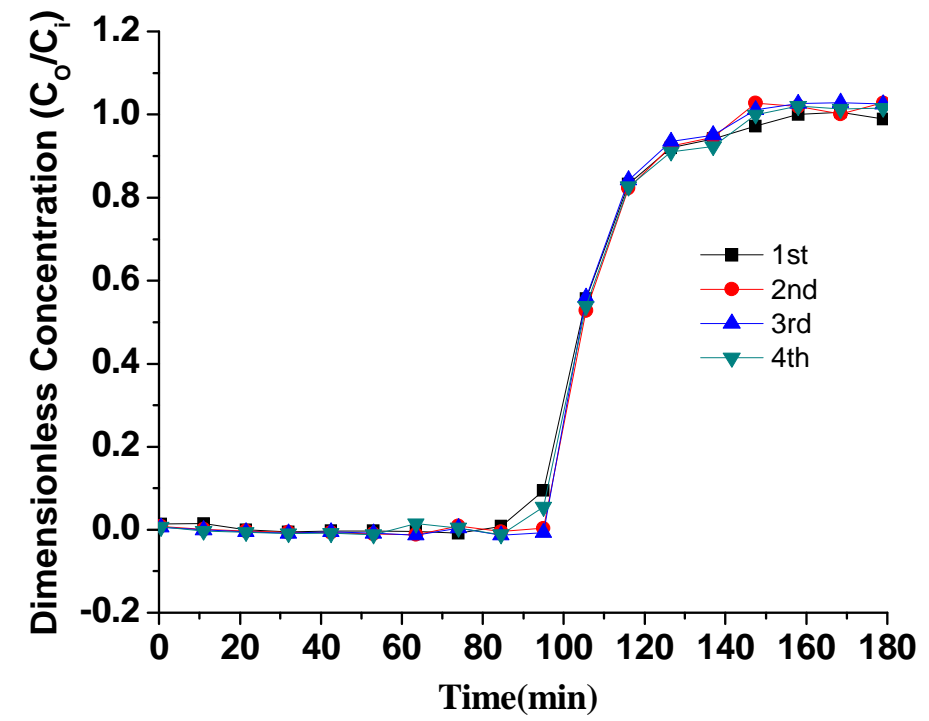

B

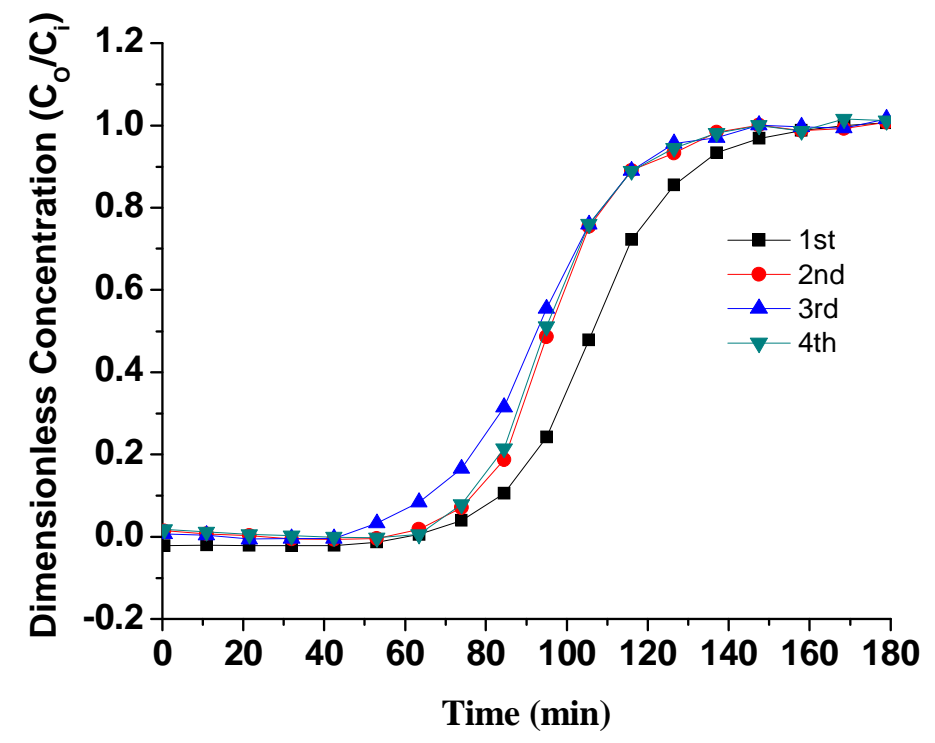

Fig. 5. (A) Repeated adsorption of butanol with unmodified AC; (B) Repeated adsorption of butanol with $6 \mathrm{M} \mathrm{HNO}_{3}$ modified AC. 


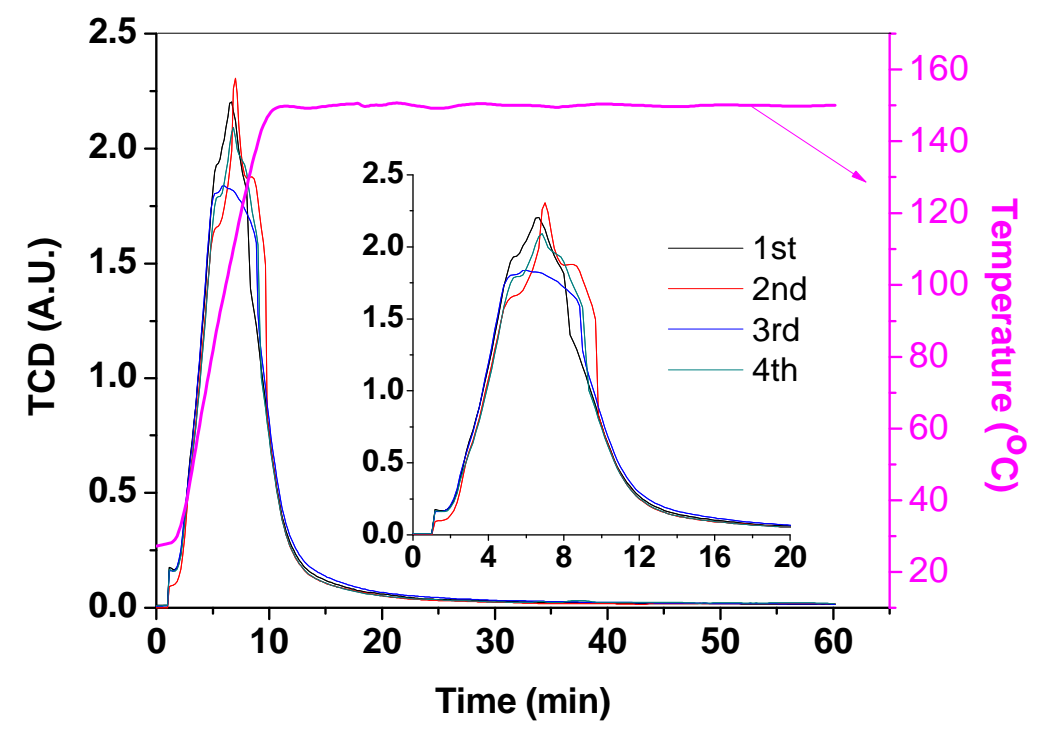

Fig. 6. Butanol desorption of $6 \mathrm{M} \mathrm{HNO}_{3}$ modified AC. 